\title{
Design of High Performance Microstrip Dual-Band Bandpass Filter
}

\author{
Nafiseh KHAJAVI ${ }^{1}$, Seyed Vahab AL-Din MAKKI ${ }^{2}$, Sohrab MAJIDIFAR ${ }^{3}$ \\ ${ }^{1}$ Dept. of Electrical Engineering, Dezful Branch, Islamic Azad University, Dezful, Iran \\ ${ }^{2}$ Dept. of Electrical Engineering, Razi University, Kermanshah, Iran \\ ${ }^{3}$ Dept. of Electrical Engineering, Kermanshah University of Technology, Kermanshah, Iran \\ n_khajavi89@yahoo.com,v.makki@razi.ac.ir,s.majidifar@razi.ac.ir
}

\begin{abstract}
This paper presents a new design of dual-band bandpass filters using coupled stepped-impedance resonators for wireless systems. This architecture uses multiple couple stubs to tune the passband frequencies and the filter characteristics are improved using defected ground structure (DGS) technique. Measurement results show insertion losses of $0.93 \mathrm{~dB}$ and $1.13 \mathrm{~dB}$ for the central frequencies of $2.35 \mathrm{GHz}$ and $3.61 \mathrm{GHz}$, respectively. This filter is designed, fabricated and measured and the results of the simulation and measurement are in good agreement.
\end{abstract}

\section{Keywords}

Dual-band bandpass filters, stepped-impedance resonators, defected ground structure (DGS), insertion loss

\section{Introduction}

Nowadays microwave systems have different applications in the society including satellite televisions, mobile phones, and civilian and military satellite systems. Given the growth in daily demand of communication systems like satellite communication and mobile phones, a contemporary trend in microwave technology can be seen towards compact and small-sized circuits and lower prices. To achieve this objective, active and passive microwave circuits are designed in a compact, multi-band and frequencyadjustable manner. After developing portable communication systems, multi-band systems have attracted great attention. Using this characteristic, results in smaller sizes and lower prices. Designing dual-band filters using loadedstub open-loop resonators is a common practice [1]. This structure has return loss of more than $3 \mathrm{~dB}$ in two bands. Dual-band bandpass filters have also been provided using spiral stepped-impedance resonators [2]. In [3] dual-band filters have been designed using defected ground structure resonator and a dual-mode open-stub loaded stepped impedance resonator. A dual mode microstrip fractal resonator is proposed in [4] and optimized perimeter of the proposed resonator by using fourth iteration $\mathrm{T}$-square fractal shape. L. C. Tsai [5] combined a wide-band bandpass filter and a band-stop filter and designed a dual-band filter. In another work, X. Guan designed dual-band filters using transmission lines and open-ended stubs [6]. A non-degenerate dual-band microstrip filter has been developed using non-degenerate resonator loads and open-ended stubs in [7]. A dual-band bandpass microstrip filter has been designed in [8] using microstrip periodic stepped-impedance ring resonators. For better description, design process of a LC model is presented in [9]. High selectivity and good suppression is obtained in [10] using embedded scheme resonator. The parallel LC resonant circuit can be represented for equivalent circuit of the DGS [11]. In other case a bandpass filter is designed using coupled DGS open loop resonators [12]. By applying the fractal theory and defected ground structure, filter dimensions have been reduced in [13].

In this paper a microstrip dual-band bandpass filter is designed using coupled stepped-impedance resonators. Designing filter is performed in three stages. To adjust the frequency of pass bands, we add a low impedance section to the middle of the basic structure. For fixed frequencies according to WLAN standards, multiple coupling structures is added to the proposed resonator and filter characteristics like return loss, insertion loss and bandwidth were enhanced using defected ground structure technique. In design process of the proposed filter, the exact combination of several known methods (resonator design base on the $\lambda / 2$-stepped impedance structure, multiple coupling- defected ground structure) is used instead of a complex dual band structure. In this method each parts of filter response is influenced by a part of the design process and complexity of the final structure is replaced with the multiplicity of design process.

\section{Filter Design}

Figure 1 shows basic structure of open-ended stepped-impedance resonator with the half-wave of $\lambda / 2$. This structure consists of a high impedance section $Z_{1}$ with the electric length of $\theta_{1}$ and two low impedance sections $Z_{2}$ with the electric length of $\theta_{2}$ as in [14]. 


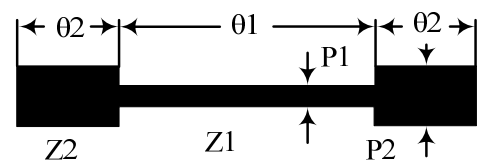

Fig. 1. Basic structure stepped-impedance resonator with the half-wave of $\lambda / 2$.

The resonance condition of the resonator can be derived by:

$$
R_{\mathrm{Z}}=Z_{2} / Z_{1}=\tan \theta_{1} \tan \theta_{2}
$$

where $R_{\mathrm{Z}}$ is the impedance ratio of the stepped impedance resonator (SIR). The fundamental frequency $f_{0}$ and first spurious frequency $f_{s b 1}$ of the resonator are related by:

$$
\frac{f_{s b 1}}{f_{0}}=\frac{\pi}{2 \tan ^{-1} \sqrt{R_{Z}}} .
$$

Figure 2 shows the normalization of the first neutral frequency as a function of $R_{\mathrm{Z}}$. By selecting a lower impedance ratio, the first neutralization mode shifts towards the upper frequency range.

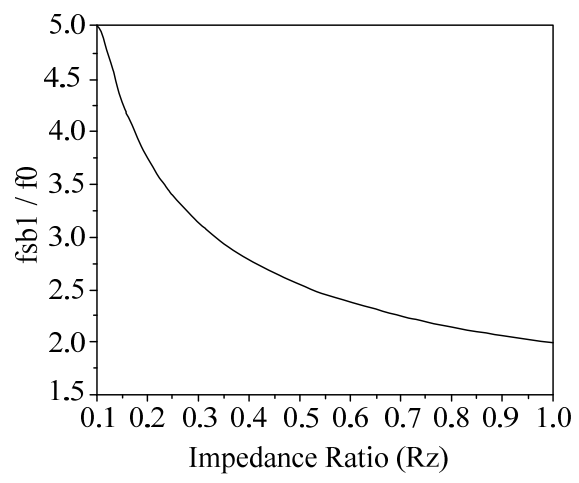

Fig. 2. Normalization of the first neutral frequency as a function of $R_{Z}$

Designing of the filter is performed in three stages:

- Resonator design.

- Adding multiple couplings to the proposed resonator for neutralize neutral harmonics in stop band.

- Using defected ground structure (DGS) technique to improve the filter characteristics.

\subsection{Resonator Design}

\subsubsection{Basic Resonator}

According to (2) and $f_{0} / f_{s b 1}=1.85$, we will have $R_{Z}$ $=1.3$. Now, if $Z_{1}=100 \Omega$, given (1), $Z_{2}=130 \Omega$. Given the values of $Z_{1}$ and $Z_{2}, \mathrm{P} 1=0.289 \mathrm{~mm}$ and $\mathrm{L} 2=0.13 \mathrm{~mm}$ are calculated. As shown in Fig. 3(a), the basic resonator is designed using structure of Fig. 1. Dimension of Fig. 3(a) are as follow: $\mathrm{L} 1=30.4 \mathrm{~mm}, \mathrm{P} 1=0.298 \mathrm{~mm}, \mathrm{~L} 2=$ $0.13 \mathrm{~mm}, \mathrm{P} 2=2.16 \mathrm{~mm}$ and $\mathrm{G}=0.1 \mathrm{~mm}$.

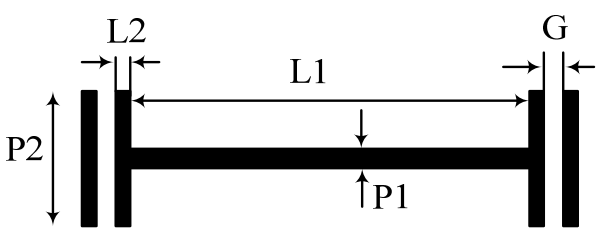

(a)

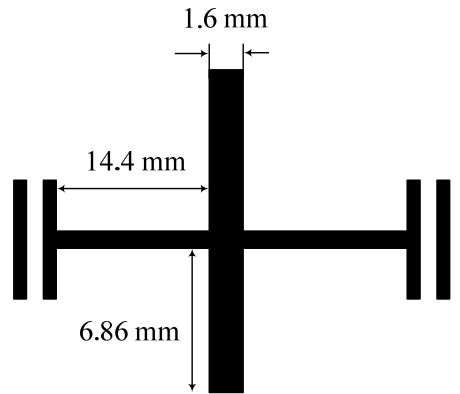

(b)

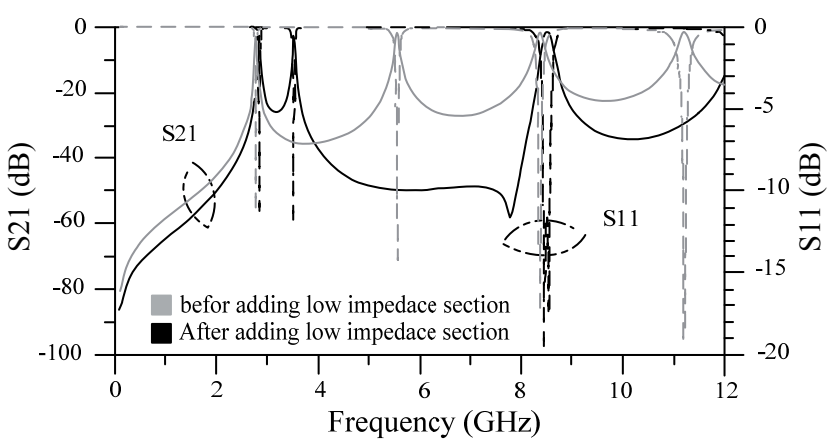

(c)

Fig. 3. Basic resonator. (a) The layout of the basic resonator. (b) The layout of the basic resonator with added low impedance section. (c) Simulation result of the part (a) and (b).

\subsubsection{Tuning of the Passband Frequencies}

In the basic resonator, the first passband frequency reaches $2.7 \mathrm{GHz}$ and the second one reaches $5.5 \mathrm{GHz}$. With adding a low impedance stub to the basic resonator (Fig. 3b), the second passband frequency shifts to the first one. Passband frequencies can be adjusted in two stages:

- By changing L1, first passband frequency is placed at a desired value.

- By changing the dimensions of the low impedance stub, while the first pass band frequency is fix, the second one tunes at the desired value.

\subsubsection{Physical Size Optimizations}

To optimize the dimensions of the filter, we change the $30.4 \mathrm{~mm}$ long middle transmission line as shown in Fig. 4(a). Dimensions of the proposed resonator are as follow: $\mathrm{W} 1=0.13 \mathrm{~mm}, \mathrm{~L} 1=0.16 \mathrm{~mm}, \mathrm{~W} 2=0.13 \mathrm{~mm}$, $\mathrm{L} 2=17.57 \mathrm{~mm}, \mathrm{~W} 3=0.186 \mathrm{~mm}, \quad \mathrm{~L} 3=1.86 \mathrm{~mm}, \quad \mathrm{~L} 4=$ $7.852 \mathrm{~mm}, \mathrm{~L} 5=14.412 \mathrm{~mm}, \mathrm{~W} 4=0.4 \mathrm{~mm}, \mathrm{~L} 6=2.4 \mathrm{~mm}$, $\mathrm{W} 5=0.43 \mathrm{~mm}, \mathrm{~L} 7=4.065 \mathrm{~mm}, \mathrm{~W} 6=0.289 \mathrm{~mm}, \mathrm{G}=0.2 \mathrm{~mm}$. 


\subsubsection{Proposed LC Model of the Resonator}

In order to better describe the designed resonator, its LC model, as it is shown in Fig. 4(b) is presented. In this model, $\mathrm{Cg}$ represents the coupling capacitance between the open stubs and the transmission lines are modeled by a Tjunction circuit including two series inductances and a central ground ended capacitor. Lt1 and Ct1 are the inductance and capacitance of L7 and Cop1, Cop2 are the capacitances of the open stubs with respect to ground. Lt2 and $\mathrm{Ct} 2$ are the inductance and capacitance of T-junction part of the middle loop. The values of circuit parameters are calculated using equations (3)-(8) [15].

$$
\begin{array}{cc}
\varepsilon_{r e f}=\frac{\varepsilon_{r}+1}{2}+\left\{\left(1+12 \frac{H}{W}\right)^{-0.5}+0.04\left(1-\frac{W}{H}\right)^{2}\right\} & \frac{W}{H} \leq 1 \\
\varepsilon_{r e f}=\frac{\varepsilon_{r}+1}{2}+\frac{\varepsilon_{r}-1}{2}\left(1+12 \frac{H}{W}\right)^{-0.5} & \frac{W}{H} \geq 1 \\
Z_{C}=\frac{120 \pi}{\frac{C_{a}}{\varepsilon_{r}} \sqrt{\varepsilon_{r e f}}} &
\end{array}
$$

where $W$ is the microstrip line width, $\varepsilon_{r}$ is the relative dielectric constant of the substrate, $H$ is the substrate thickness, $Z_{C}$ is the characteristic impedance, $\varepsilon_{r e f}$ is the effective dielectric constant, $C_{a}$ is the capacitance per unit length with the dielectric substrate replaced by air and $c$ is the velocity of electromagnetic waves in free space $(c=$ $\left.3.0 \times 10^{8} \mathrm{~m} / \mathrm{s}\right) . C_{a}$ can be determined by (5).

$$
\begin{array}{ll}
C_{a}=\frac{2 \pi \varepsilon_{r}}{l_{n}\left(\frac{8 H}{W}+\frac{W}{4 H}\right)} & \frac{W}{H} \leq 1 \\
C_{a}=\varepsilon_{r}\left(\frac{W}{H}+1.393+0.66 l_{n}\left(\frac{W}{H}+1.444\right)\right) & \frac{W}{H} \geq 1
\end{array}
$$

While $l$ is the length of the microstrip line, $L$ and $C$ as inductance and capacitance of microstrip line can be determined by (6) and (7).

$$
\begin{gathered}
L=\frac{Z_{C} l}{V_{P}}, \\
C=\frac{l}{Z_{C} V_{P}}
\end{gathered}
$$

$V_{p}$ is the phase velocity and can be determined by (8).

$$
V_{p}=\frac{c}{\sqrt{\varepsilon_{r e f}}}
$$

The calculated values of the circuit parameters are as follow: $\mathrm{L}=0.08 \mathrm{nH}$, Cop1 $=0.346 \mathrm{pF}, \mathrm{Cg}=0.3 \mathrm{pF}$, Cop2 $=0.36 \mathrm{pF}, \mathrm{Lt} 1=1.09 \mathrm{nH}, \mathrm{Ct} 1=0.17 \mathrm{pF}, \mathrm{Lt} 2=3.916 \mathrm{nH}$ and $\mathrm{Ct} 2=0.67 \mathrm{pF}$. The electromagnetic (EM) and LC simulated results of this structure are shown in Fig. 4(c). As it is shown, good agreement between the EM and LC simulated results is achieved. This resonator is designed on Ro 4003 substrate with 3.38 dielectric constant, 20 mil heights and 0.0021 loss tangent.

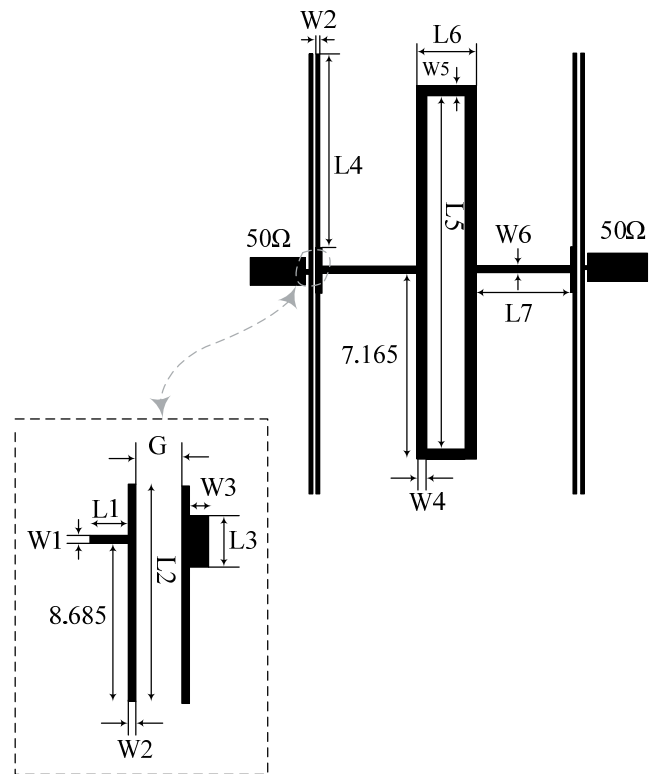

(a)

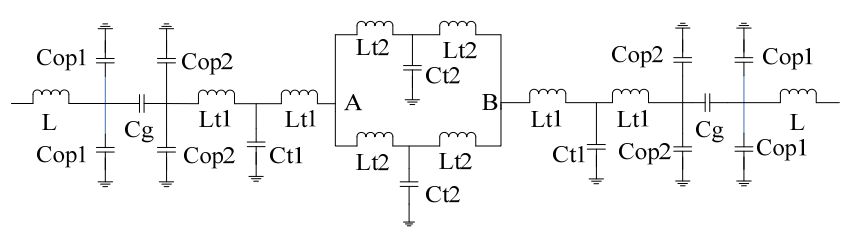

(b)

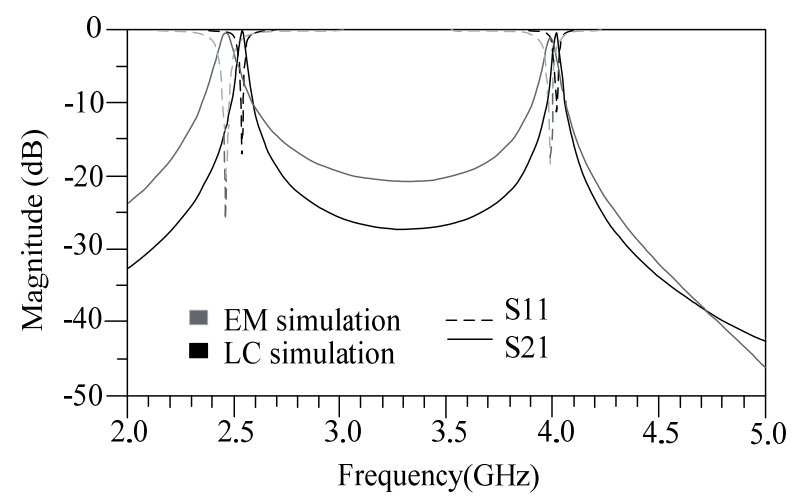

(c)

Fig. 4. Proposed resonator. (a) The layout of the proposed resonator. (b) LC equivalent circuit of the proposed resonator. (c) EM and LC circuit simulated results.

The frequency response of the proposed resonator in a wide span is shown in Fig. 5. As can be seen in this figure, this resonator has two bands with the central frequencies of $\mathrm{f}_{1}=2.40 \mathrm{GHz}$ and $\mathrm{f}_{2}=4.0 \mathrm{GHz}$. The objective is to design a dual-band bandpass filter with the same central frequencies as those of WLAN. Central frequency of the first band is fixed on $2.4 \mathrm{GHz}$, while in the second band our goal is to achieve central frequency of $3.7 \mathrm{GHz}$. These bands have insertion losses of $0.478 \mathrm{~dB}$ and $1.137 \mathrm{~dB}$, return losses of $26.05 \mathrm{~dB}$ and $18.549 \mathrm{~dB}$ and bandwidths of $76 \mathrm{MHz}$ and $49 \mathrm{MHz}$, respectively. In order to achieve the better response characteristics of the resonator, the following changes should be considered: balancing the insertion loss of two bands, decreasing the return loss of two 
bands and increasing the passbands' bandwidth. Furthermore, the neutral harmonic at the $6.866 \mathrm{GHz}$ decreases the stopband bandwidth.

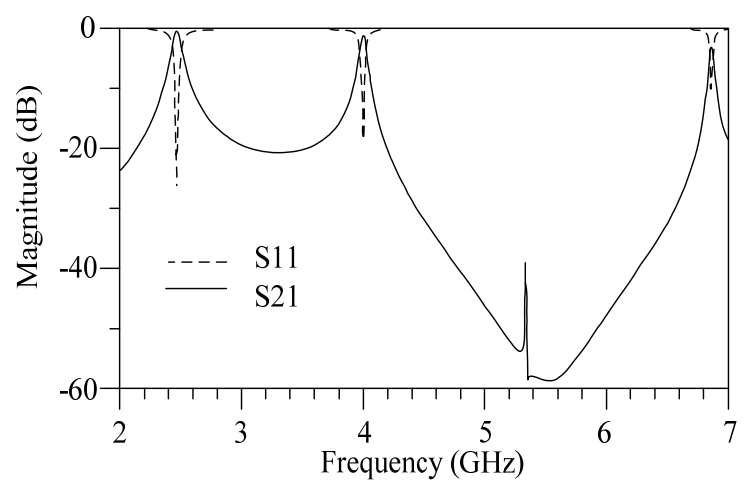

Fig. 5. Frequency response of the proposed resonator in a wide span.

\subsection{Adding Multiple Couplings to the Proposed Resonator for Neutralizing Neutral Harmonics in the Stopband}

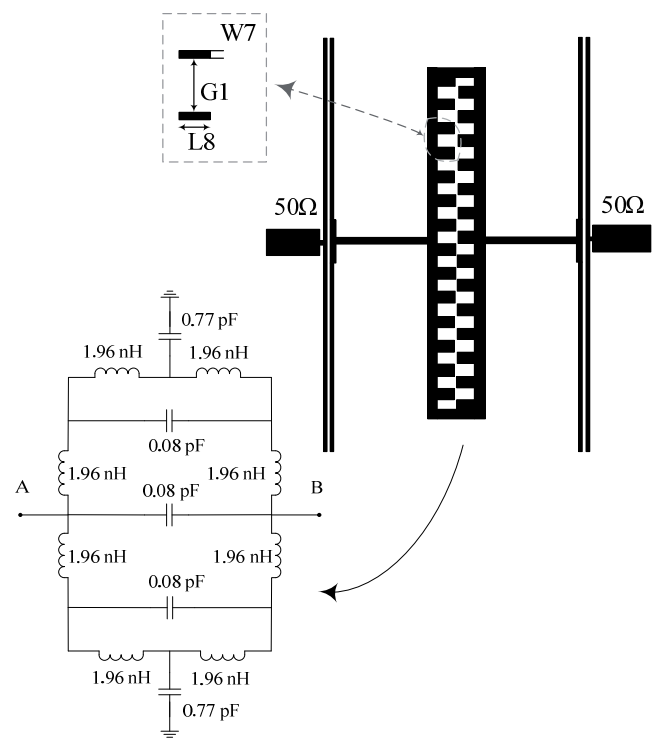

(a)

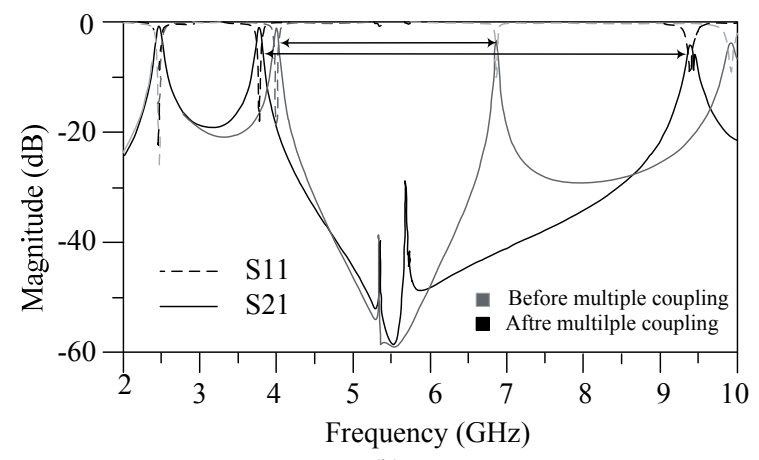

(b)

Fig. 6. The proposed filter (a) Layout and LC model (b) Compares between frequency responses of the proposed resonator and the proposed filter.
One of the problems in the last stage is the limited stopband bandwidth. This problem can be solved using multiple couplings. Figure 6(a) shows the proposed filter. In this filter the added multiple coupling are located inside the middle lope of the resonator. The dimensions of these coupling stubs are as follow: W7 $=0.524 \mathrm{~mm}, \mathrm{~L} 8=$ $0.762 \mathrm{~mm}, \mathrm{G} 1=0.524 \mathrm{~mm}$. The size and number of the coupling stubs and its LC model are depicted in Fig. 6(a). In this model the Lt 2 is divided into two parts and the effects of the multiple couplings are depicted with added coupling capacitors and increased grounded capacitors. Simulation results of the proposed filter are shown in Fig. 6(b).

As it is shown in Fig. 6(b), this method suppresses the harmonics from $4.2 \mathrm{GHz}$ to $9.377 \mathrm{GHz}$, increases the stopband bandwidth and sets the second passband at the 3.7 GHz. In the proposed filter, the first and second passbands have insertion losses of $0.521 \mathrm{~dB}$ and $0.842 \mathrm{~dB}$, return losses of $25.3 \mathrm{~dB}$ and $17.914 \mathrm{~dB}$ and bandwidths of $77 \mathrm{MHz}$ and $61 \mathrm{MHz}$, respectively. This results show that return loss is increased but passband bandwidth is improved in two bands. In the next stage we try to increase the passbands bandwidth and achieve modified return loss in two bands.

\subsection{Using Defected Ground Structure (DGS) Technique to Improve the Filter Characteristics}

Figure 7 shows the applied defected ground structure and its LC model to improve the filter characteristics. In this filter, improvement of the passband performance and also increasing the bandwidth of each band are the reasons of DGS utilization. Dumbbell and rectangular shape were used in defected ground structure technique. As it is shown in Fig. 7(a) the dumbbell shaped DGS is introduced by a parallel LC resonator and this part is added to the LC model of the multiple couplings. The rectangular shape DGS is applied to moderate the effect of the bends (on both sides of the central line).

The dimensions of the dumbbell parts and rectangular planes are as follow: $\mathrm{W} 8=0.9 \mathrm{~mm}, \mathrm{~L} 9=2.79 \mathrm{~mm}, \mathrm{~W} 9=$ $0.198 \mathrm{~mm}, \quad \mathrm{~L} 10=3.33 \mathrm{~mm}, \quad \mathrm{~L} 11=0.89 \mathrm{~mm}, \quad \mathrm{~L} 12=$ $1.69 \mathrm{~mm}, \mathrm{~L} 13=0.34 \mathrm{~mm}$. A picture of the fabricated filter and the results of the simulation and measurement of the final filter are depicted in Fig. 7(b) and Fig. 7(c), respectively. EM simulations are performed in ADS and measurement performed using the Agilent network analyzer N5230A.

Figure 8 shows the current density distribution at the surface of the filter, with/without DGS. As it is shown in Fig. 8(a) and Fig. 8(b), dumbbell shaped DGS is utilized because of the balanced increasing at the current density distribution of the filter and this has improved the filter response in the passbands (in terms of insertion loss, bandwidth and return loss).From Fig. 8(c) it is apparent that the 


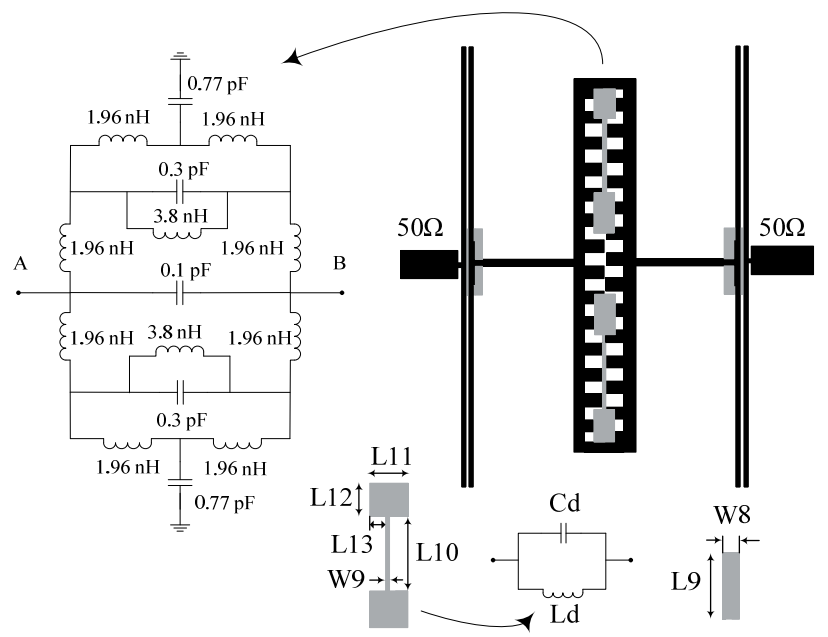

(a)

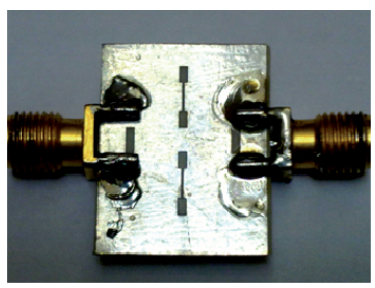

Bottom of the final filter

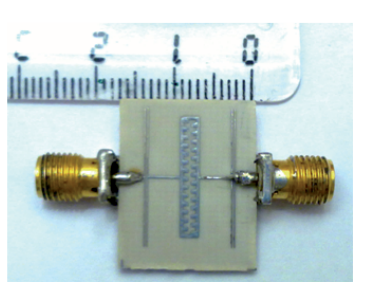

Top of the final filter (b)

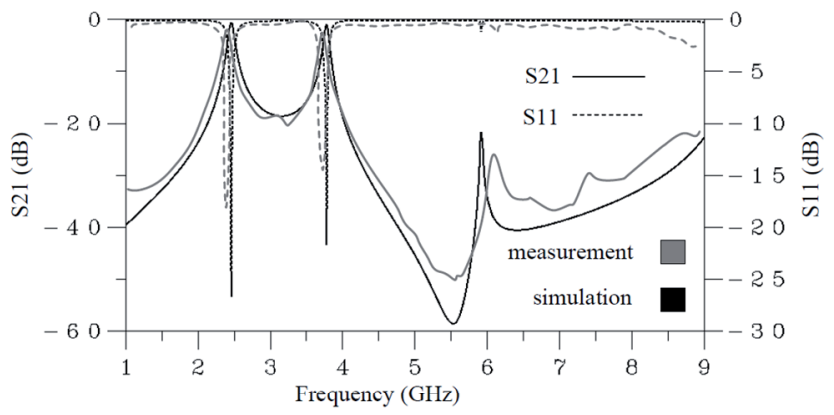

(c)

Fig. 7. Final filter. (a) Layout and LC model of the proposed filter. (b) A picture of the fabricated filter. (c) Simulation and measurement results of the filter.

\begin{tabular}{|c|c|c|c|}
\hline $\begin{array}{c}\text { Characteristics of } \\
\text { proposed resonator } \\
\text { and proposed filter }\end{array}$ & $\begin{array}{c}\mathrm{S}_{21} \text { in the } \\
\text { first and } \\
\text { second } \\
\text { passband } \\
\text { respectively } \\
(\mathrm{dB})\end{array}$ & $\begin{array}{c}\mathrm{S}_{11} \text { in the first } \\
\text { and second } \\
\text { passband } \\
\text { respectively } \\
(\mathrm{dB})\end{array}$ & $\begin{array}{c}\text { Bandwidth in } \\
\text { the first and } \\
\text { second } \\
\text { passband } \\
\text { respectively } \\
(\mathrm{MHz})\end{array}$ \\
\hline $\begin{array}{c}\text { Proposed resonator } \\
\text { (without multiple } \\
\text { coupling) }\end{array}$ & $\begin{array}{c}-0.478 \&- \\
1.137\end{array}$ & $\begin{array}{c}-26.05 \&- \\
18.549\end{array}$ & $76 \& 49$ \\
\hline $\begin{array}{c}\text { Proposed filter } \\
\text { (using multiple } \\
\text { coupling) }\end{array}$ & $-0.521 \&-$ \\
0.842 & $-25.3 \&-$ \\
17.914 & $77 \& 61$ \\
\hline $\begin{array}{c}\text { Final structure of } \\
\text { the proposed filter } \\
\text { (using DGS } \\
\text { technique) }\end{array}$ & $-0.457 \&-$ & $-23.57 \&-$ & $95 \& 87$ \\
\hline
\end{tabular}

Tab. 1. Compares between response characteristics of proposed structures in passbands.

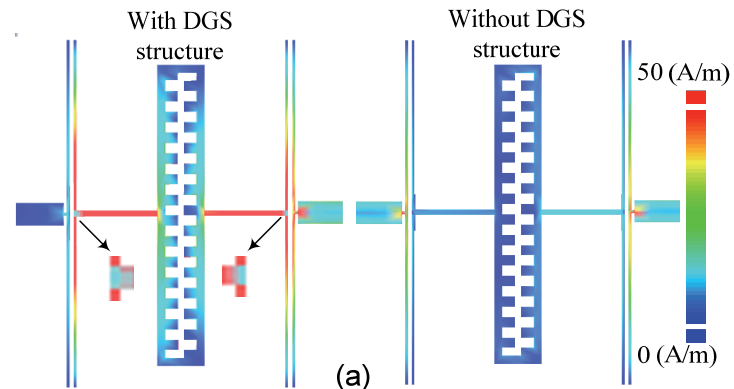

(a)

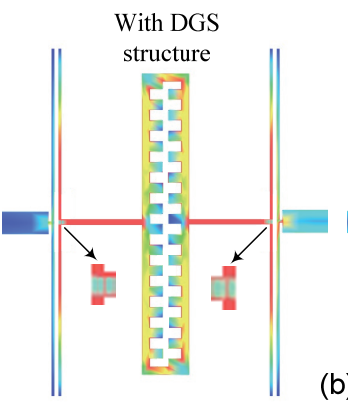

Without DGS

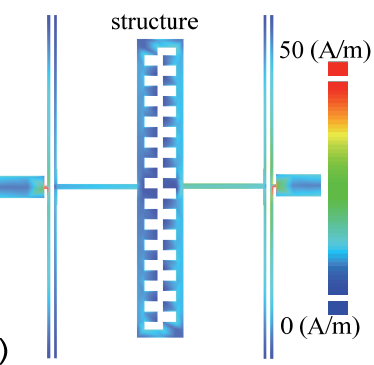

With DGS

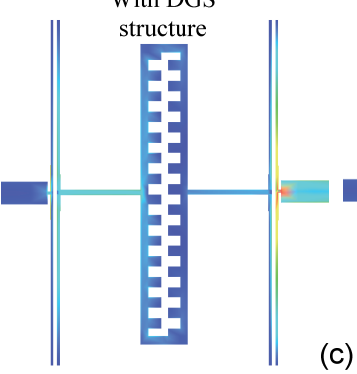

Without DGS

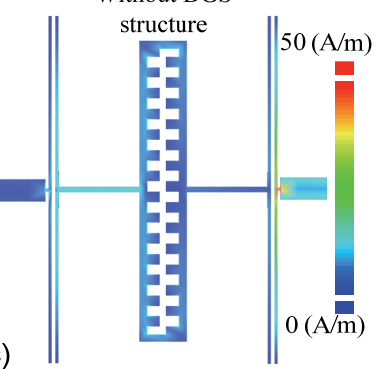

(c)

Fig. 8. Current density distribution at the surface of the filter: (a) at $2.45 \mathrm{GHz}$; (b) at $3.7 \mathrm{GHz}$; (c) at $3.07 \mathrm{GHz}$.

current density distribution of the filter with/ without DGS has no obvious change at $3.07 \mathrm{GHz}$ (as the isolation frequency between two bands). So dumbbell shaped DGS has improved the passband performance of the filter. Also, the isolation between passbands and stopband characteristics has not been changed. The bends affect on the high frequency harmonics. In order to decrease the effects of these bends, the rectangular shaped DGS is utilized. As Figures 8 (a) and 8 (b) indicate the current density distribution of the bends is fixed using rectangular shaped DGS (while the current density distribution is increased in other lines) and the effects of them are limited. A comparison between the response characteristics of the proposed structures (in term of passbands) is shown in Tab. 1.

\section{Conclusion}

In this paper, at the first, using specified relations, a basic structure is designed. In order to shift the closest harmonic as the second passband towards the first passband, and also, to attenuate other harmonics, we added a low impedance stub to the middle of the basic structure. Using this structure, the proposed resonator for optimization of dimensions is provided. In order to further suppress the harmonics, and also to fix frequencies according to WLAN standards, multiple coupling structures are added 
to the proposed resonator. Finally, DGS technique was applied to improve filter response specifications. In final structure of the filter, frequency of the first and second passbands are $2.35 \mathrm{GHz}$ and $3.61 \mathrm{GHz}$ respectively, which have return losses of $0.93 \mathrm{~dB}$ and $1.13 \mathrm{~dB}$ and insertion losses of $17.56 \mathrm{~dB}$ and $14.08 \mathrm{~dB}$ and bandwidths of $89 \mathrm{MHz}$ and $81 \mathrm{MHz}$, respectively.

\section{References}

[1] MONDAL, P., MANDAL, M. K. Design of dual-band bandpass filters using stub-loaded open-loop resonators. IEEE Transactions on Microwave Theory and Techniques, 2008, vol. 56, no. 1, p. 150-155. DOI: 10.1109/TMTT.2007.912204

[2] GUO, L., YU, Z., ZHANG, Y. A dual-band band-pass filter using stepped impedance resonator. Microwave and Optical Technology Letters, 2011, vol. 53, no. 1, p. 123-125. DOI: 10.1002/mop.25648

[3] WANG, L., GUAN, R. Novel compact and high selectivity dualband BPF with wide stopband. Radioengineering, 2012, vol. 21, no. 1 , p. $492-495$

[4] AHMED, E. S. Dual-mode dual-band microstrip bandpass filter based on fourth iteration T-square fractal and shorting pin. Radioengineering, 2012, vol. 21, no. 2, p. 617-623.

[5] YUN, T. S., NOH, S. K., KIM, OH, E. K., SON, H. M., LEE, J. C. Compact dualband bandpass filter with two transmission zeros using dual-mode microstrip resonator and tapped-line geometry. Microwave and Optical Technology Letters, 2011, vol. 53, no. 1, p. 108-111. DOI: $10.1002 / \operatorname{mop} .25627$

[6] TSAI, L. C., HSUE, C. W. Dual-band bandpass filters using equallength coupled-serial-shunted line and Z-transform technique. IEEE Transactions on Microwave Theory and Techniques, 2004, vol. 52, no. 4, p. 1111-1117. DOI: 10.1109/TMTT.2004.825680

[7] GUAN, X., MA, Z., CAI, P., KOBAYASHI, Y., ANADA, T., HAGIWARA, G. Synthesis of dual-band bandpass filters using successive frequency transformation and circuit conversions. IEEE Transactions on Microwave and Wireless Components Letters, 2006, vol. 16, no. 3, p. 110-112. DOI: 10.1109/LMWC.2006. 869868

[8] SHETA, A. F. Narrow band compact non-degenerate dual-mode microstrip filter. In Proceedings of the 25th National Radio Science Conference. Egypt, 2008.

[9] MAKKI, S. V. AL-DIN, AHMADI, A., MAJIDIFAR, S., SARIRI, H., RAHMANI, Z. Sharp resonator microstrip LPF using folded stepped impedance open stubs. Radioengineering, 2013, vol. 22, no. 1, p. $328-329$

[10] ZONG, B. F., WANG, G. M., ZENG, H. Y., WANG, Y. W. Compact and high performance dual-band bandpass filter using resonator-embedded scheme for WLANs. Radioengineering, 2012, vol. 21 , no. 4 , p. $1050-1053$.

[11] PARUI, S. K., DAS S. A new defected ground structure for different microstrip circuit applications. Radioengineering, 2007, vol. 16 , no. 1 , p. 16-22.

[12] VAGNER, P., KASAL, M. A novel bandpass filter using a combination of open-loop defected ground structure and half-wavelength microstrip resonators. Radioengineering, 2010, vol. 19, no. 3, p. 392-396.

[13] KUFA, M., RAIDA, Z. Comparison of planar fractal filters on defected ground substrate. Radioengineering, 2012, vol. 21, no. 4, p. 1019-1024.

[14] SARKAR, P., GHATAK, R., PODDAR, D. R. A dual-band bandpass filter using SIR suitable for WiMAX band. In International Conference on Information and Electronics Engineering IPCSIT. (Malaysia), 2011.

[15] HONG, J. S., LANCASTER, M. J. Microstrip Filters for RF/ Microwave Applications. A Wiley-Interscience Publication. John Wiley \& Sons, 2001. ISBN 0-471-38877-7

\section{About the Authors...}

Nafiseh KHAJAVI received the B.Sc. degree in Medical Engineering from Islamic Azad University Dezful Branch, 2008, and the M.Sc. degree in Electrical Engineering from Kermanshah Science and Research Branch, Islamic Azad University, Kermanshah, 2012. She has been with the Department of Engineering, Islamic Azad University Dezful Branch. Her research interests include microstrip filter, the analysis and design of high-frequency electronics and microwave passive circuits.

Seyed Vahab Al-Din MAKKI was born in Kermanshah. $\mathrm{He}$ received his $\mathrm{PhD}$ in Electrical Engineering-Waves from Khaje Nasir Toosi University in 2008. He is with the Electrical Engineering Department of Razi University in Kermanshah and Islamic Azad University, Kermanshah Branch, since 2008. His current research interests include modern digital radio propagation systems, microwave devices and radio transmitters.

Sohrab MAJIDIFAR received his B.Sc. and M.Sc. in Electrical Engineering from Razi University in 2009 and 2011, respectively. He joined Kermanshah University of Technology in 2011 as a lecturer. His research interests include microwave passive circuits and RFIC. 